\title{
Determinants of Postpartum Intrauterine Contraceptive Device Uptake among Women Delivering in Public Hospitals of South Gondar Zone, Northwest Ethiopia, 2019: An Unmatched Case-Control Study
}

\author{
Mandefro Assefaw $\mathbb{D D}^{1}{ }^{1}$ Getnet Azanew, ${ }^{2}$ Ayenew Engida, ${ }^{2}$ Zenebe Tefera ${ }^{\mathbb{D}}{ }^{1}$ \\ and Wondimnew Gashaw $\mathbb{I D}^{1}$ \\ ${ }^{1}$ Department of Midwifery, College of Medicine and Health Science, Wollo University, Dessie, Ethiopia \\ ${ }^{2}$ Department of Midwifery, College of Medicine and Health Science, University of Gondar, Gondar, Ethiopia \\ Correspondence should be addressed to Mandefro Assefaw; mandefroassefaw@gmail.com
}

Received 22 May 2020; Revised 31 January 2021; Accepted 6 February 2021; Published 22 February 2021

Academic Editor: Diego Raimondo

Copyright (c) 2021 Mandefro Assefaw et al. This is an open access article distributed under the Creative Commons Attribution License, which permits unrestricted use, distribution, and reproduction in any medium, provided the original work is properly cited.

\begin{abstract}
Introduction. Integrated use of postpartum intrauterine contraceptive devices with delivery service during the immediate postpartum period is ideal for both women and health-care providers. However, utilization of intrauterine contraceptive devices during the postpartum period was rare and in Ethiopia, with information regarding uptake of postpartum intrauterine contraceptive devices limited. Objective. Identify determinants of postpartum intrauterine contraceptive devices uptake among women delivering in public hospitals of South Gondar zone, Northwest Ethiopia, 2019. Methods. An unmatched case-control study was conducted in public hospitals of South Gondar, Ethiopia, from August 1, 2019, to November 10, 2019. A total of 140 cases and 280 controls have actively participated in the study. Five hospitals were selected by simple random sampling. Cases were selected consecutively, whereas two controls for each case were recruited by the lottery method. Pretested questionnaires were used to collect data and it was entered into Epidata version 4.4.2. Logistic regression analysis was used to identify variables associated with the use of outcome and adjusted odds ratio with a 95\% confidence interval was used to determine the association between independent and outcome variables. Results. Completing secondary education (AOR = 4.5, 95\%CI 2.3-8.85), having a total number of children of $3-4(\mathrm{AOR}=3.6,95 \% \mathrm{CI} 1.25-10.2)$, having $\geq 5(\mathrm{AOR}=4.7,95 \% \mathrm{CI} 1.5-15.3)$, attending 3 antenatal care $(\mathrm{AOR}=2.8,95 \% \mathrm{CI} 1.44-5.6)$, ever hearing about postpartum IUCD (AOR =6.6, 95\%CI 2.7-16.1), and having counseling from health-care provider about a postpartum intrauterine contraceptive device (AOR $=6.2,95 \% \mathrm{CI} 2.99-12.8$ ) were significantly associated with uptake of the postpartum intrauterine contraceptive. Conclusion and Recommendation. Completing secondary education, having 3-4 and $\geq 5$ children, attending three antenatal care, ever hearing about postpartum IUCD, and having counseling from health-care providers about the postpartum intrauterine contraceptive device among women were significantly associated with uptake of an intrauterine contraceptive device after birth. Therefore, it is better to advise women to strictly follow their antenatal care, access to information, and provide counseling.
\end{abstract}

\section{Introduction}

Postpartum intrauterine contraceptive devices are a provision of IUCD vaginally within 10 minutes after removal of the placenta, called postplacental IUCD, or it can be inserted within 2 days (morning of the first postpartum day before discharge to home) after vaginal delivery, called early postpartum intrauterine contraceptive device. PPIUCD also can be provided during intracesarean after expulsions of the placenta before uterine closure [1].

The immediate postpartum period provides an opportunity for women to initiate effective long-acting 
contraceptive methods because they are motivated to prevent early subsequent conceptions and have access to health care and this is the ideal time to be certain that the women are not pregnant $[1,2]$. The insertion of IUCD during the postpartum period does not affect breast milk, has a lower rate of uterine perforation, does not have other major side effects, and is time-saving and cost-effective, because it can be inserted within few minutes and provided in the same setting with delivery service, and it also reduces crowding of outpatient family planning unit $[1,3]$. Therefore, for developing countries, integrated use of PPIUCD with delivery service is the best opportunity to prevent unintended pregnancy. The unmet needs of family planning also can be reduced by providing it immediately after childbirth without a need for repeated visiting of the health-care system and are very convenient for women who will be unable to return for contraception purposes [4]. Despite this advantage, uptake of a postpartum intrauterine contraceptive device during early and immediate postpartum periods is low [5-8]. Reports from the study done at bale zone health facility showed that PPIUCD acceptance was $12.4 \%$ [6] and at Sidama zone, PPIUCD utilization was only $21 \%$ [7]. The main reason for this low utilization of PPIUCD might be due to the negative contribution of different sociodemographic and obstetric factors.

Even if little researches were conducted in Ethiopia about the postpartum intrauterine contraceptive device, most of them also focused on the proportion of IUCD acceptance and utilization [5-7]. Besides, those researches included factors such as sociodemographic and obstetric related characters; it was not sufficient to show full information about determinants of a postpartum intrauterine contraceptive device, because of sociodemographic characteristic variation throughout different regions of the country.

From most reports of the previous study, the prevalence of postpartum intrauterine contraceptive devices is also rare. Therefore, this study design was appropriate to dig out a full picture of determinants for postpartum intrauterine contraceptive device uptake within a short period. Therefore, the purpose of this study is to fill these gaps by identifying major determinant factors of postpartum intrauterine contraceptive device uptake.

\section{Methods and Materials}

2.1. Study Area and Period. An unmatched case-control study was conducted in South Gondar zones public hospitals such as Debretabor general hospital, Mekane-eyesuse primary hospital, Wogeda primary hospital, Addis Zemen primary hospital, and Nifas Mewucha primary hospital from August 1, 2019, to November 10, 2019. South Gondar is one of the zones found in Amhara region and its capital city is Debretabor, which is found $666 \mathrm{~km}$ far from Addis Ababa, capital city of Ethiopia. There are eight hospitals found in the zone, which serve $2,609,823$ populations. Other maternal and family planning services were given without payment in all public hospitals. Currently, CUT 380 PPIUCD is available in all hospitals.
2.2. Study Design. A facility-based unmatched case-control study design was conducted.

\subsection{Population}

2.3.1. Source Population. The source population is all postpartum women who gave birth in public hospitals of South Gondar zone, during the study period.

2.3.2. Study Population. All postpartum women delivering in selected public hospitals during the study period and using a postpartum intrauterine contraceptive device within the first 48 hours following vaginal delivery and intracaesarean after the expulsion of the placenta before uterine closure were considered as cases. However, all postpartum women who gave birth in the same hospitals but did not use postpartum intrauterine contraceptive devices were considered as controls.

\subsection{Inclusion and Exclusion Criteria}

2.4.1. Inclusion Criteria. Postpartum women who gave birth by any mode of delivery in the selected public hospitals were included.

2.4.2. Exclusion Criteria. Women who gave birth by any mode of delivery in selected public hospitals but did not fulfill WHO medical eligibility criteria for PPIUCD during the study period were excluded [9].

\subsection{Sample Size Determination and Procedure}

2.5.1. Sample Size Determination. The sample size for the study was determined with double population proportion formula by using Epi info version 7 statistical software program for an unmatched case-control study. The calculation considered the following assumptions: 95\% confidence interval, $80 \%$ power, $1: 2$ ratio of cases to controls, with a plan to have another child as the exposure variable, $47.7 \%$ of PPIUCD users and $32.8 \%$ of nonusers with exposure [7], and 10\% nonresponse rate as compensation for both groups. Therefore, 450 postpartum women (150 cases and 300 controls) were included in the study. The sample size for each selected public hospital was proportionally allocated based on previous monthly average PPIUCD utilization.

2.5.2. Sampling Method and Procedures. In south Gondar, there are eight hospitals, and about five (63\%) of them were selected by simple random sampling methods. Then the number of PPIUCD utilizations per three months was obtained from each selected public hospital's quarterly report to calculate average monthly cases flow. Cases were identified by asking them whether or not they use IUCD after delivery and by crosschecking their charts and they were selected consecutively, and as soon as cases were identified 
two controls were selected by simple random methods to increase the power of the study.

\subsection{Study Variables}

2.6.1. Dependent Variables. Uptake of a postpartum intrauterine contraceptive device was a dependent variable.

\subsubsection{Independent Variables}

(i) Sociodemographic variables are as follows:

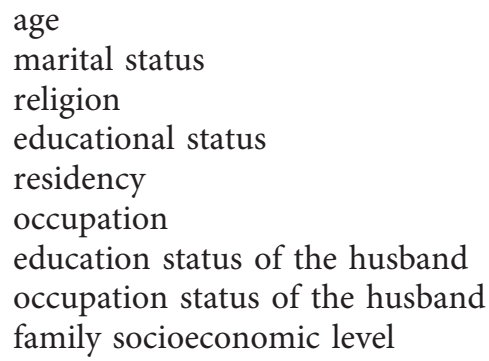

(ii) Family planning-related factors are as follows:

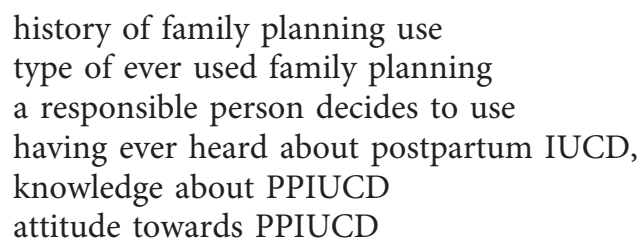

(iii) Obstetric, reproductive, and health service-related variables are as follows:

family size
parity
number of live children that women have
sex composition of live children
birth interval
status of current birth
desire to have children

\subsection{Operational Definition}

Uptake of PPIUCD is the actual usage of IUCD during the first 48 hours after birth and before discharge to home following any mode of delivery [7].

Counseling is considered when health-care providers inform women of at least either of the benefits, side effects, duration of pregnancy, and prevention of PPIUCD [7].

Knowledge about PPIUCD was determined by considering the mean score of correctly answered knowledge assessed questions as a cut point. Postpartum women who answered above or below the mean score of 7 knowledge assessed questions were considered knowledgeable or not knowledgeable, respectively [6].

Attitude-assessing questions were rated by (disagree, neutral, and agree). Then the response for each item was added by using three Likert scale analyses. Therefore, participants answer above the mean score categorized as having a positive attitude and the reverse categorized as negative attitude [6].

2.8. Data Collection Procedures and Instrument. Data were collected using a pretested, semistructured, and intervieweradministered questionnaire. The questionnaire was adapted by reviewing similar researches conducted previously [5-7, 10-12]. The questionnaire involves sociodemographic, obstetric, reproductive, maternal health care, and family planning-related variables. Initially, the questionnaire was prepared in the English version then it was translated into the local language. Five trained BSc midwives and two BSc nurses have participated in data collection and supervisor, respectively. One data collector was assigned to each hospital.

2.9. Data Quality Control. To assure the quality of data, the tool was tested by interviewing $5 \%$ of postpartum women who gave birth at Gina Mechawocha and Este health center two weeks before the actual data collection and a necessary correction was applied. Half-day training had been given for data collectors and supervisors about the purpose of the study, data collection procedures, and ways of communicating by the principal investigator. Continuous observation of the data collection process and its completeness was assessed every two weeks.

2.10. Data Processing and Analysis. At the end of data collection, completeness of data was checked; coding was implemented and entered into Epidata version 4.4.2.1. Statistical software and exported to SPSS version 23 software for further analysis. Descriptive variables were presented using tables and charts.

Bivariate binary logistic regression was used to assess the association between PPIUCD uptake and each factor separately. All variables with $p$ value less than or equal to 0.2 in the bivariate logistic regression were entered into the multivariable logistic regression model. Multivariable logistic regression was done by using a backward likelihood ratio method to control potential confounders. Correlation between independent variables was done to check multicollinearity. Finally, the adjusted odds ratio with $95 \%$ confidence interval was determined to measure the strength of association, and a $p$ value less than 0.05 was used to determine the significant association between factors and outcome variables.

2.11. Ethical Consideration. The study obtained ethical clearance from the research review commute of the school of midwifery on behalf of the University of Gondar ethical review board. Written permission was obtained from the responsible body of the South Gondar zone health office and each selected hospital's medical director after approval consent letter was submitted. Verbal informed consent was 
secured, after the purpose of the study was explained to each study participant.

\section{Result}

3.1. Sociodemographic Characters of Respondents. A total of 420 postpartum women (140 cases and 280 controls) were successfully interviewed during the data collection period making a response rate of $93.3 \%$. The median ages of cases and controls were 33 and 28 years, respectively. Regarding the educational status of women, only thirty-six $(25.7 \%)$ of cases had no formal education. However, nearly half (47.5\%) of controls had no formal education. Sixty-five (48.1\%) and one hundred forty-five (52\%) spouses of cases and controls had no formal education, respectively. Among the participants, twelve $(8.6 \%)$ cases and forty-five (14.6\%) controls were unmarried currently. The majority of cases (97.1\%) and controls (98.2\%) were Amhara. More than half (55.7\%) of cases and nearly half (49.3\%) of controls lived in a rural area (Table 1).

3.2. Obstetric and Reproductive Characteristics. Both cases and controls have been interviewed regarding their obstetric and reproductive characters. The majority of cases (55\%) and controls (57.5\%) had a family size of 3-4 followed by $\geq 5$ family size for both cases and controls. From respondents, only nine (6.4\%) cases and fifty-eight (20.4\%) controls did not have a live child at all. Most of the cases $(87.9 \%)$ and controls $(69.3 \%)$ were multiparous.

Concerning the sexual status of live children that women had, eighty-two (62.6\%) of the case and hundred twenty-five (56.3\%) of controls had both male and female children. Among multiparous women, sixty-four (52\%) and one hundred twenty-five (64.4\%) cases and controls, respectively, have birth interval greater than 36 months. Among women who planned to have a child, forty-four $(35.7 \%)$ of cases and seventy-eight (43.6\%) of controls desire to have $1-2$ children. In addition to this, only two $(2.7 \%)$ of cases and two $(1.1 \%)$ of controls want to be pregnant within the first 24 months (Table 2 and Figure 1).

\subsection{Family Planning-Related Characteristics of Participants.} The majority of cases (83.6\%) and controls (90.4\%) used different modern contraceptive methods before the last pregnancy. However, injectable method was the most frequent usable contraceptive method used by both cases, sixtysix $(56.4 \%)$, and controls, one hundred seventy-three $(68.4 \%)$, as compared to other methods. One hundred thirty-two (94\%) cases and one hundred fifty-six (55.7\%) controls heard about the postpartum intrauterine contraceptive device (Table 3, Figures 2 and 3 ).

3.4. Knowledge of Participants about Postpartum IUCD. Eighty-two $(58.6 \%)$ of cases and one hundred sixteen $(41.4 \%)$ of controls heard that IUCD can be inserted immediately and $68(48.6 \%)$ of cases and 108 (38.6\%) of controls knew that IUCD is a contraceptive method which
TABLE 1: Sociodemographic characters of respondents who gave birth in South Gondar public hospitals, Northwest Ethiopia, 2019.

\begin{tabular}{|c|c|c|}
\hline \multirow[b]{2}{*}{ Characteristics } & \multicolumn{2}{|c|}{ Uptake of PPIUCD } \\
\hline & $\begin{array}{c}\text { Cases } n=140 \\
(\%)\end{array}$ & Controls $n=280(\%)$ \\
\hline \multicolumn{3}{|l|}{ Age of women in a year } \\
\hline $15-24$ & $24(17.1 \%)$ & $68(24.3 \%)$ \\
\hline $25-34$ & $59(42.1 \%)$ & $161(57.5 \%)$ \\
\hline $35-44$ & $57(40.7 \%)$ & $51(18.2 \%)$ \\
\hline \multicolumn{3}{|c|}{ Educational status of women } \\
\hline No formal education & $36(25.7 \%)$ & $133(47.5 \%)$ \\
\hline Primary & $26(18.6 \%)$ & $59(21.1 \%)$ \\
\hline Secondary & $58(41.4 \%)$ & $47(16.8 \%)$ \\
\hline Higher education & $20(14.3 \%)$ & $41(14.6 \%)$ \\
\hline \multicolumn{3}{|c|}{ Occupational status of women } \\
\hline Housewife & $79(56.4 \%)$ & $188(67.1 \%)$ \\
\hline Daily laborer & $18(12.9 \%)$ & $21(7.5 \%)$ \\
\hline Merchant & $7(7.7 \%)$ & $16(5.7 \%)$ \\
\hline $\begin{array}{l}\text { Government } \\
\text { employee }\end{array}$ & $15(10.7 \%)$ & $32(11.4 \%)$ \\
\hline Private employee & $9(6.4 \%)$ & $7(2.5 \%)$ \\
\hline Student & $12(8.6 \%)$ & $16(5.7 \%)$ \\
\hline \multicolumn{3}{|c|}{ Husband occupational status } \\
\hline Farmer & $65(47.8 \%)$ & $125(46.3 \%)$ \\
\hline Daily laborer & $14(11 \%)$ & $25(9.3 \%)$ \\
\hline Merchant & $15(10 \%)$ & $48(17.8 \%)$ \\
\hline $\begin{array}{l}\text { Government } \\
\text { employee }\end{array}$ & $22(16.2 \%)$ & $51(18.9 \%)$ \\
\hline Private employee & $9(6.6 \%)$ & $12(4.5 \%)$ \\
\hline Student & $10(7.4 \%)$ & $9(3.3 \%)$ \\
\hline \multicolumn{3}{|l|}{ Family wealth index } \\
\hline Lowest & $50(35.7 \%)$ & $121(43.2 \%)$ \\
\hline Middle & $55(39.3 \%)$ & $34(12.1 \%$ \\
\hline Highest & $35(25 \%)$ & $125(44.6 \%)$ \\
\hline
\end{tabular}

$a=$ Oromo, Tigre, $b=$ Muslim, Protestant, and Catholic, $c=$ single, separated, divorced, and widowed.

prevents pregnancy at least 10 years. Sixty (43\%) of cases and ninety-three (33\%) of controls correctly answered questions about how PPIUCD did not increase the risk of sexually transmitted disease and more than half of cases (54\%) and hundred-two (36.4\%) of controls knew that IUCD does not interfere with sexual activity. Therefore, the mean of correctly answered knowledge assessed items was $2.92 \pm 2 \mathrm{SD}$. Then $28(20 \%)$ of cases and $127(45.4 \%)$ of controls were not knowledgeable and $112(80 \%)$ of cases and about 153 $(54.6 \%)$ of controls were considered knowledgeable (Table 4).

3.5. Level of Attitude towards PPIUCD. Among the total respondents, $55.4 \%$ of cases and $68.6 \%$ of controls had a negative attitude towards postpartum intrauterine contraceptive devices. However, $44.6 \%$ of cases and $31.4 \%$ of controls had positive attitudes towards postpartum intrauterine contraceptive device (Table 5).

3.6. Determinants of Postpartum Intrauterine Contraceptive Device Uptake. Bivariate binary logistic regression was conducted to detect the association between each 
TABle 2: Obstetric, reproductive, and maternal health-care characteristics of respondents delivering in public hospitals of South Gondar zone, Ethiopia, 2019 ( $n=140$ cases and 280 controls).

\begin{tabular}{|c|c|c|}
\hline \multirow[b]{2}{*}{ Characteristics } & \multicolumn{2}{|c|}{ Uptake of PPIUCD } \\
\hline & $\begin{array}{c}\text { Cases } n=140 \\
(\%)\end{array}$ & Controls $n=280(\%)$ \\
\hline \multicolumn{3}{|l|}{ Total family size } \\
\hline$\leq 2$ & $12(8.6 \%)$ & $45(16.1 \%)$ \\
\hline $3-4$ & $77(55 \%)$ & $161(57.5 \%)$ \\
\hline$\geq 5$ & $51(36.4 \%)$ & $74(26.4 \%)$ \\
\hline \multicolumn{3}{|c|}{ No. of total live children women have } \\
\hline No children at all & $9(6.4 \%)$ & $58(20.4 \%)$ \\
\hline $1-2$ & $48(34.3 \%)$ & $137(48.9 \%)$ \\
\hline $3-4$ & $51(36.4 \%)$ & $47(16.8 \%)$ \\
\hline$\geq 5$ & $32(22.9 \%)$ & $38(13.6 \%)$ \\
\hline \multicolumn{3}{|c|}{ Sex status of live children $(\mathbf{n} \mathbf{1}=\mathbf{1 3 1}, \mathbf{n} \mathbf{2}=\mathbf{2 2 2})$} \\
\hline Only female & $16(12.2 \%)$ & $35(15.8 \%)$ \\
\hline Only male & $33(25.2 \%)$ & $62(27.9 \%)$ \\
\hline Both male and female & $82(62.6 \%)$ & $125(56.3 \%)$ \\
\hline \multicolumn{3}{|l|}{ Parity of respondents } \\
\hline Primipara & $17(12.1 \%)$ & $86(30.7 \%)$ \\
\hline Multipara & $123(87.9 \%)$ & $194(69.3 \%)$ \\
\hline \multicolumn{3}{|c|}{ Birth interval by months $(\mathrm{n} 1=123, \mathrm{n} 2=194)$} \\
\hline Less than 24 & $46(37.4 \%)$ & $47(24.2 \%)$ \\
\hline $26-36$ & $13(10.6 \%)$ & $22(11.3 \%)$ \\
\hline Greater than 36 & $64(52 \%)$ & $125(64.4 \%)$ \\
\hline \multicolumn{3}{|c|}{ Did you have the plan to have a child? } \\
\hline Yes & $73(52.1 \%)$ & $179(63.9 \%)$ \\
\hline No & $59(42.1 \%)$ & $69(24.6 \%)$ \\
\hline Undecided & $8(5.7 \%)$ & $32(11.4 \%)$ \\
\hline \multicolumn{3}{|c|}{ No. of children you plan to have $(\mathbf{n} 1=73, \mathbf{n} 2=179)$} \\
\hline $1-2$ & $44(35.7 \%)$ & $78(43.6 \%)$ \\
\hline $3-4$ & $25(30.5 \%)$ & $78(43.6 \%)$ \\
\hline$\geq 5$ & $4(5.4 \%)$ & $23(12.8 \%)$ \\
\hline \multicolumn{3}{|c|}{ Sex status of children women desire $(\mathbf{n} 1=73, \mathbf{n} 2=179)$} \\
\hline Only male & $9(12.3 \%)$ & $19(10.6 \%)$ \\
\hline Only female & $5(6.8 \%)$ & $6(3.4 \%)$ \\
\hline Both & $5980.8 \%)$ & $154(86 \%)$ \\
\hline \multicolumn{3}{|c|}{ Decision maker for planned children $(\mathrm{n} 1=\mathbf{7 3}, \mathrm{n} 2=179)$} \\
\hline Myself & $20(27.4 \%)$ & $54(30.1 \%)$ \\
\hline Husband & $31(41.3 \%)$ & $58(32.4 \%)$ \\
\hline Joint decision & $22(30.1 \%)$ & $67(37.4 \%)$ \\
\hline \multicolumn{3}{|c|}{ Time to have children by month $(\mathbf{n} 1=73, \mathbf{n} 2=179)$} \\
\hline Less than 24 & $2(2.7 \%)$ & $2(1.1 \%)$ \\
\hline $24-36$ & $22(30.1 \%)$ & $100(55.9 \%)$ \\
\hline Greater than 36 & $49(67.1 \%)$ & $77(43 \%)$ \\
\hline \multicolumn{3}{|l|}{ Status of current birth } \\
\hline Planned & $123(87.9 \%)$ & $233(83.2 \%)$ \\
\hline Unplanned & $17(12.1 \%)$ & $47(16.8 \%)$ \\
\hline \multicolumn{3}{|l|}{ Number of ANC visits } \\
\hline Did not attend & $28(20 \%)$ & $96(34.3 \%)$ \\
\hline Attended one times & $8(5.7 \%)$ & $30(10.7 \%)$ \\
\hline Attended two times & $9(6.4 \%)$ & $47(16.8 \%)$ \\
\hline Attended three times & $68(18.6 \%)$ & $64(22.9 \%)$ \\
\hline Attended $\geq 4$ times & $27(19.3 \%)$ & $43(15.4 \%)$ \\
\hline \multicolumn{3}{|l|}{ Counseling } \\
\hline Yes & $126(90 \%)$ & $121(43.2 \%)$ \\
\hline No & $14(10 \%)$ & $159(56.8 \%)$ \\
\hline
\end{tabular}

TABle 2: Continued.

\begin{tabular}{lcc}
\hline & \multicolumn{2}{c}{ Uptake of PPIUCD } \\
Characteristics & $\begin{array}{c}\text { Cases } n=140 \\
(\%)\end{array}$ & Controls $n=280(\%)$ \\
\hline Partner involvement for discussion $(\mathbf{n} \mathbf{1}=\mathbf{1 2 6}, \mathbf{n} \mathbf{2}=\mathbf{1 2 1})$ \\
Yes & $65(51.6 \%)$ & $50(41.3 \%)$ \\
No & $61(48.4 \%)$ & $71(58.7 \%)$ \\
\hline Time of counseling $(\mathbf{n 1}=\mathbf{1 2 6}, \mathbf{n} \mathbf{2}=\mathbf{1 2 1})$ & \\
During ANC & $34(27 \%)$ & $13(11.2 \%)$ \\
During LFSOL & $23(18.3 \%)$ & $15(12.9 \%)$ \\
During PNC & $28(22.2 \%)$ & $34(20.7 \%)$ \\
Multiple counseling a & $41(32.5 \%)$ & $59(55.2 \%)$ \\
\hline
\end{tabular}

$\mathbf{a}=$ woman who had counseled more than one time, $\mathbf{n} \mathbf{1}=$ cases and $\mathbf{n} \mathbf{2}=$ controls, $\mathbf{A N C}=$ antenatal care, $\mathbf{L F S O L}=$ latent first stage of labor, PNC $=$ postnatal care.

independent variable with the outcome variable. Therefore, thirteen variables with $p$ value equal to or less than 0.2 were added to the multivariable logistic regression model.

Multivariable logistic regression analysis was done to identify determinants of postpartum intrauterine contraceptive device uptake. Therefore, completing secondary education, having a total number of live children $[3,4]$ and $\geq 5$, attending three ANC visits during the last pregnancy, having ever heard about the postpartum intrauterine contraceptive device, and having counseling from health-care providers about PPIUCD were significantly associated with uptake of PPIUCD.

In multivariable analysis, women who had completed secondary education were 4.5 times more likely to uptake postpartum intrauterine contraceptive devices than women who had no formal education ( $\mathrm{AOR}=4.5,95 \% \mathrm{CI} 2.25-8.9$ ).

Compared to those who had no live child, women who had 3-4 and $\geq 5$ live children were 3.6 times $(A O R=3.6,95 \%$ CI 1.25-10.24) and 4.7 times ( $\mathrm{AOR}=4.7,95 \% \mathrm{CI} 1.46-15.3$ ), respectively, more likely to uptake postpartum intrauterine contraceptive device.

The study also identified that women having 3 ANC follow-ups were 2.8 times more likely to uptake postpartum intrauterine contraceptive device as compared to those who did not attend antenatal care during their last pregnancy $(\mathrm{AOR}=2.8,95 \% \mathrm{CI}=1.1 .44-5.6)$. In addition to this, women who ever heard about PPIUCD were 6.6 times more likely to uptake PPIUCD (AOR 6.6 (95\%CI, 2.7-16.1)) as compared to their counterparts.

Finally, the odds of using PPIUCD among women who had got counseling from health-care providers regarding PPIUCD were 6.2 times those among women who did not counsel health-care providers $\quad(\mathrm{AOR}=6.2 \quad(95 \% \mathrm{CI}$, 2.99-12.85)) (Table 6).

\section{Discussion}

This study identified that factors including completing secondary education, having the number of live children 3-4 and greater or equal to five, attending three ANC visits 


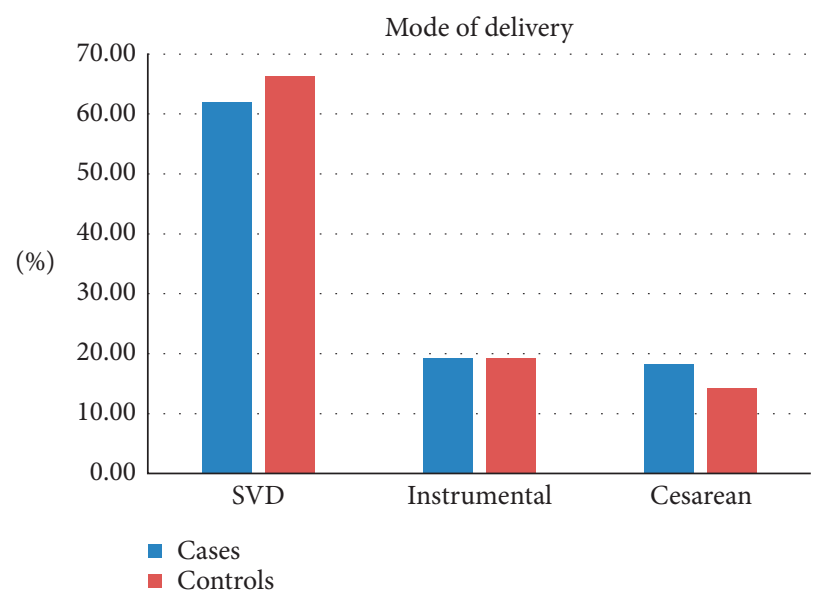

FIGURE 1: Mode of delivery among respondents delivering in public hospitals of South Gondar zone, Ethiopia, 2019 ( $n=140$ cases and 280 controls).

TABLE 3: Family planning-related characteristics of respondents delivering in selected public health hospitals of South Gondar zone, Ethiopia, 2019 ( $n=140$ cases and 280 controls).

\begin{tabular}{|c|c|c|}
\hline \multirow{2}{*}{ Characteristics } & \multicolumn{2}{|c|}{ Uptake of PPIUCD } \\
\hline & Cases $n=140(\%)$ & Controls $n=280(\%)$ \\
\hline \multicolumn{3}{|c|}{ Ever used family planning before the last PX } \\
\hline Yes & $117(83.6 \%)$ & $253(90.4 \%)$ \\
\hline No & $23(16.4 \%)$ & $27(9.6 \%)$ \\
\hline \multicolumn{3}{|l|}{ Type of modern family planning ever used $^{\mathrm{a}}$} \\
\hline Pill & $37(31.6 \%)$ & $69(27.3 \%)$ \\
\hline Injectable & $66(56.4 \%)$ & $173(68.4 \%)$ \\
\hline Implants & $43(36.8 \%)$ & $67(26.5 \%)$ \\
\hline IUCD & $15(12.8 \%)$ & $7(27.7 \%)$ \\
\hline \multicolumn{3}{|l|}{ Who decides to ever use family planning? } \\
\hline Myself & $33(28.2 \%)$ & $82(32.4 \%)$ \\
\hline Husband & $10(8.5 \%)$ & $14(5.5 \%)$ \\
\hline Other (health-care provider, family) & $74(63.2 \%)$ & $157(60.5 \%)$ \\
\hline \multicolumn{3}{|l|}{ Ever heard about PPIUCD } \\
\hline Yes & $132(94 \%)$ & $156(55.7 \%)$ \\
\hline No & $8(5.7 \%)$ & $124(44.3 \%)$ \\
\hline
\end{tabular}

$\mathbf{a}=$ more than one answer is possible, $\mathbf{p x}=$ pregnancy, $\mathbf{I U C D}=$ intrauterine contraceptive device. $\mathbf{P P I U C D}=$ postpartum intrauterine contraceptive device.

during last pregnancy, having ever heard about PPIUCD, and having counseling from health-care providers regarding postpartum intrauterine contraceptive device as contraceptive were significantly associated with uptake of the postpartum intrauterine contraceptive device.

This study showed that women who had completed secondary education were more likely to use the postpartum intrauterine contraceptive device as compared to those who had no formal education. This finding contradicts the result reported from the research done in the health facilities of Nigeria [13]. This difference may be due to the difference in the study area and a long time elapse between the two studies. However, the finding was comparable with the result reported from the study done at West Denpasar [14] at Bahirdar [5] and supported by the study done at Bale Zone health facilities [6]. The possible justification for this may be that women who had completed secondary education may have better understanding of the information obtained from health-care providers, media, and other sources. Educated respondents might understand and reject misconceptions, and they may use this method.

The study also observed that women having $3-4$ and $\geq 5$ live children were significantly likely to uptake postpartum intrauterine contraceptive devices than those who did not have children previously. The finding was supported by similar results from a study done at the private health facilities of Nigeria [13]. The possible explanation for this finding is that women who have a large number of children may be motivated to prevent further pregnancy to limit her family size.

This study also identified that women who had 3 antenatal care follow-ups throughout their last pregnancy were more likely to use the postpartum intrauterine contraceptive device as compared to those who did not attend ANC. The 


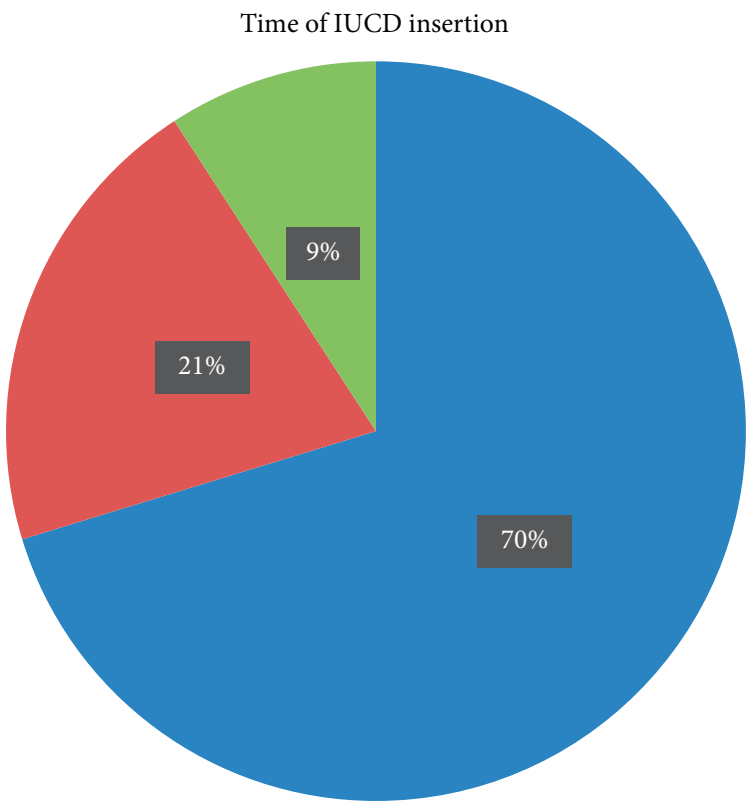

Within 10 minutes of vaginal birth

10 min-2 days of vaginal birth

Intracesarean

FIGURE 2: Time of insertion of the postpartum intrauterine contraceptive device among respondents delivering in public hospitals of South Gondar, Ethiopia, $2019(n=140)$. Other = includes family, relatives, and friend.

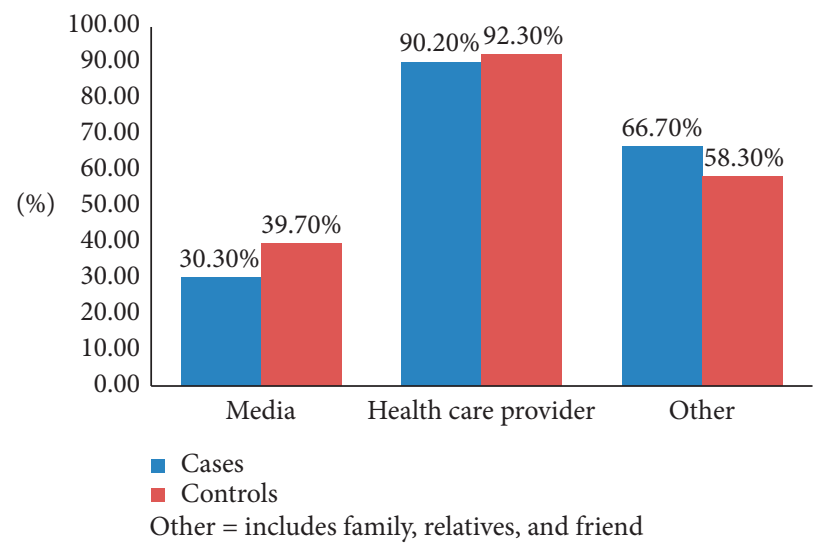

Figure 3: Distribution of information source about family planning among respondents delivering in public hospitals of South Gondar zone, Ethiopia, 2019 ( $n=132$ cases and 156 controls).

result is consistent with the study done at bale zone health facilities, Ethiopia [6]. This may be due to the fact that focused antenatal care recommends counseling about contraceptive methods during antenatal care follow-up and that should start from their third visit and it is the ideal time to counsel women about family planning to use during the postpartum period [15]. Therefore, the increased frequency of ANC follow-ups to three times may allow pregnant women to access an opportunity for discussion about the postpartum intrauterine contraceptive device as other methods.

The study observed that women who ever heard about the postpartum intrauterine contraceptive device were more likely to use them than their counterparts. The result is consistent with the study done at Sidama public health facility [7], since, from EDHS 2016 reports, still, the overall utilization of intrauterine contraceptive devices is rare, less than $2 \%$ [9], which may be attributed to lack of information 
TABle 4: Knowledge about PPIUCD among respondents delivering in public hospitals of South Gondar zone, Northwest Ethiopia, December 2019 ( $n=140$ cases and 280 controls).

\begin{tabular}{|c|c|c|c|c|}
\hline \multirow{2}{*}{ Variable } & \multicolumn{4}{|c|}{ Uptake of PPIUCD } \\
\hline & \multicolumn{2}{|c|}{ Cases $n=140(\%)$} & \multirow{2}{*}{$\begin{array}{c}\text { Controls } n=280(\%) \\
116(41.4 \%)\end{array}$} & \multirow{2}{*}{$\begin{array}{r}\text { Total } \\
198\end{array}$} \\
\hline \multirow{2}{*}{ IUCD can be inserted immediately after delivery } & Yes & $82(58.6 \%)$ & & \\
\hline & No & $58(41.4 \%)$ & $164(58.6 \%)$ & 222 \\
\hline \multirow{2}{*}{ IUCD prevents pregnancy for at least 10 years } & Yes & $68(48.6 \%)$ & $108(38.6 \%)$ & 176 \\
\hline & No & $72(51.4 \%)$ & $172(61.4 \%)$ & 244 \\
\hline \multirow{2}{*}{ IUCD is a contraceptive method that can be put in the uterus. } & Yes & $75(53.6 \%)$ & $99(35.4 \%)$ & 174 \\
\hline & No & $65(46.4 \%)$ & $181(64.6 \%)$ & 246 \\
\hline \multirow{2}{*}{ IUCD does not increase the risk of STI } & Yes & $60(42.9 \%)$ & $93(33.2 \%)$ & 153 \\
\hline & No & $80(57.1 \%)$ & $187(66.8 \%)$ & 267 \\
\hline \multirow{2}{*}{ IUCD does not interfere with sexual activity } & Yes & $76(54.3 \%)$ & $102(36.4 \%)$ & 178 \\
\hline & No & $64(45.7 \%)$ & $178(63.6 \%)$ & 242 \\
\hline \multirow{2}{*}{ Pregnancy is immediately reversible after removal of IUCD } & Yes & $75(53.6 \%)$ & $102(36.4 \%)$ & 177 \\
\hline & No & $65(46.4 \%)$ & $178(63.6 \%)$ & 243 \\
\hline \multirow{2}{*}{ IUCD does not cause cancer of genital tract } & Yes & $69(49.6 \%)$ & $91(32.5 \%)$ & 160 \\
\hline & No & $71(51,4 \%)$ & $189(67.5 \%)$ & 260 \\
\hline
\end{tabular}

TABle 5: Participants attitudes towards PPIUCD among women who gave birth at public hospitals of South Gondar, Ethiopia, 2019 ( $n=140$ cases and 280 controls).

\begin{tabular}{|c|c|c|c|}
\hline \multirow{2}{*}{ Variable } & \multirow{2}{*}{ Category } & \multicolumn{2}{|c|}{ Uptake of PPIUCD } \\
\hline & & Cases $n=140(\%)$ & Controls $n=280(\%)$ \\
\hline \multirow{3}{*}{ Insertion and removal PPIUCD did not have severe pain } & Disagree & $71(50.7 \%)$ & $112(40 \%)$ \\
\hline & Neutral & $62(44.3 \%)$ & $95(33.9 \%)$ \\
\hline & Agree & $7(5 \%)$ & $73(26.1 \%)$ \\
\hline \multirow{3}{*}{ PPIUCD should not cause irregular vaginal bleeding } & Disagree & $62(44.3 \%)$ & $106(37.9 \%)$ \\
\hline & Neutral & $69(49.3 \%)$ & $99(35.4 \%)$ \\
\hline & Agree & $9(6.4 \%)$ & $75(26.8 \%)$ \\
\hline \multirow{3}{*}{ PPIUCD should not cause loss of privacy } & Disagree & $57(40.7 \%)$ & $89(31.8 \%)$ \\
\hline & Neutral & $76(54.3 \%)$ & $106(37.9 \%)$ \\
\hline & Agree & $7(5 \%)$ & $85(30.4 \%)$ \\
\hline \multirow{3}{*}{ PPIUCD should not restrict normal activity } & Disagree & $55(39.3 \%)$ & $81(28.9 \%)$ \\
\hline & Neutral & $78(55.7 \%)$ & $120(42.9 \%)$ \\
\hline & Agree & $7(5 \%)$ & $79(28.2 \%)$ \\
\hline \multirow{3}{*}{ PPIUCD should impair future fertility } & Disagree & $48(34.3 \%)$ & $86(30.7 \%)$ \\
\hline & Neutral & $78(55.7 \%)$ & $112(40 \%)$ \\
\hline & Agree & $14(10 \%)$ & $82(29.3 \%)$ \\
\hline \multirow{3}{*}{ PPIUCD should not rust inside the womb } & Disagree & $52(37.1 \%)$ & $88(31.4 \%)$ \\
\hline & Neutral & $72(51.4 \%)$ & $101(36.1 \%)$ \\
\hline & Agree & $16(11.4 \%)$ & $91(32.5 \%)$ \\
\hline \multirow{3}{*}{ PPIUCD should not be stuck on the fetal head if px occur during IUCD in-situ } & Disagree & $62(44.3 \%)$ & $92(32.9 \%)$ \\
\hline & Neutral & $52(37.1 \%)$ & $92(32.9 \%)$ \\
\hline & Agree & $26(18.6 \%)$ & $96(34.3 \%)$ \\
\hline \multirow{3}{*}{ PPIUCD is not for use by only older women but also for all. } & Disagree & $55(39.3 \%)$ & $104(37.1 \%)$ \\
\hline & Neutral & $64(45.7 \%)$ & $89(31.8 \%)$ \\
\hline & Agree & $21(15 \%)$ & $87(31.1 \%)$ \\
\hline \multirow{3}{*}{ PPIUCD should not move around the body } & Disagree & $68(48.6 \%)$ & $109(38.9 \%)$ \\
\hline & Neutral & $49(35 \%)$ & $85(30.4 \%)$ \\
\hline & Agree & $23(16.4 \%)$ & $86(30.7 \%)$ \\
\hline \multirow{3}{*}{ PPIUCD should not damage womb } & Disagree & $61(43.6 \%)$ & $107(38.2 \%)$ \\
\hline & Neutral & $55(39.3 \%)$ & $93(33.2 \%)$ \\
\hline & Agree & $24(17.1 \%)$ & $80(28.6 \%)$ \\
\hline
\end{tabular}


TABLE 6: Bivariate and multivariable logistic regression analysis of determinant factors for the uptake of PPIUCD among women delivering in public hospitals of South Gondar zone, Ethiopia, 2019 ( $n=140$ cases and 280 controls).

\begin{tabular}{|c|c|c|c|c|}
\hline \multirow{2}{*}{ Variables } & \multicolumn{2}{|c|}{ Uptake of PPIUCD } & \multirow{2}{*}{ COR $(95 \% \mathrm{CI}$} & \multirow{2}{*}{ AOR (95\%CI } \\
\hline & Cases $(n=140)$ & Controls (280) & & \\
\hline \multicolumn{5}{|l|}{ Age of women by years } \\
\hline $15-24$ & 24 & 68 & 1 & 1.00 \\
\hline $25-34$ & 59 & 161 & $1.04(0.6-1.81)^{*}$ & $0.8(0.37-1.60)$ \\
\hline $35-44$ & 57 & 51 & $3.2(1.7-5.77)$ & $2.1(0.84-5.43)$ \\
\hline \multicolumn{5}{|l|}{ Marital status } \\
\hline Unmarried & 12 & 41 & 1.00 & 1.00 \\
\hline Married & 128 & 239 & $1.8(0.93-3.6)^{*}$ & $1.93(0.74-5.0)$ \\
\hline \multicolumn{5}{|l|}{ Women educational status } \\
\hline No formal education & 36 & 133 & 1.00 & 1.00 \\
\hline Primary & 26 & 59 & $1.63(0.9-2.94)^{*}$ & $1.2(0.6-2.57)$ \\
\hline Secondary & 58 & 47 & $4.56(2.7-7.77)^{*}$ & $4.5(2.3-8.85)^{* *}$ \\
\hline Higher & 20 & 41 & $1.8(0.94-3.45)^{*}$ & $1.7(0.76-3.98)$ \\
\hline \multicolumn{5}{|l|}{ Family size } \\
\hline$\leq 2$ & 12 & 45 & 1 & 1.00 \\
\hline $3-4$ & 77 & 161 & $1.8(0.9-3.58)^{*}$ & $1.4(0.53-3.4)$ \\
\hline$\geq 5$ & 51 & 74 & $2.6(1.3-5.36)^{*}$ & $1.14(0.42-3.1)$ \\
\hline \multicolumn{5}{|l|}{ Total no. of live children } \\
\hline No child at all & 9 & 57 & 1 & 1.00 \\
\hline $1-2$ & 48 & 137 & $2.2(1.0-4.82)^{*}$ & $1.8(0.69-4.7)$ \\
\hline $3-4$ & 51 & 47 & $6.9(3.1-15.4)^{*}$ & $3.6(1.25-10.2)^{* *}$ \\
\hline$\geq 5$ & 32 & 38 & $5.3(2.3-12.4)^{*}$ & $4.7(1.5-15.3)^{* *}$ \\
\hline \multicolumn{5}{|l|}{ Parity } \\
\hline Primipara & 17 & 86 & 1.00 & 1.00 \\
\hline Multipara & 123 & 194 & $3.2(1.8-5.66)^{*}$ & $0.84(0.3-2.5)$ \\
\hline \multicolumn{5}{|l|}{ Plan to have children } \\
\hline No & 59 & 69 & 1 & \\
\hline Undecided & 8 & 32 & $0.3(0.13-0.68)^{*}$ & $0.45(0.14-1.42)$ \\
\hline Yes & 73 & 179 & $0.5(0.3-0.74)^{*}$ & $0.5(0.27-1.03)$ \\
\hline \multicolumn{5}{|c|}{ Frequency of ANC follow-up } \\
\hline Did not attend & 28 & 96 & 1.00 & 1.00 \\
\hline Attended one & 8 & 30 & $0.9(0.4-2.22)$ & $0.5(0.16-1.54)$ \\
\hline Attended two & 9 & 47 & $0.66(0.29-1.5)$ & $0.3(0.11-0.84)$ \\
\hline Attended three & 68 & 64 & $3.64(2.1-6.3)^{*}$ & $2.8(1.44-5.6)^{* *}$ \\
\hline Attended $\geq 4$ & 27 & 43 & $2.2(1.14-4.1)^{*}$ & $2.05(0.9-4.8)$ \\
\hline \multicolumn{5}{|c|}{ Ever use of family planning } \\
\hline No & 23 & 27 & 1 & 1.00 \\
\hline Yes & 117 & 253 & $0.5(0.3-0.99)^{*}$ & $0.5(0.22-1.2)$ \\
\hline \multicolumn{5}{|c|}{ Ever heard about PPIUCD } \\
\hline No & 8 & 124 & 1 & 1.00 \\
\hline Yes & 132 & 156 & $13.1(6.2-27.8)^{*}$ & $6.6(2.7-16.1)^{* *}$ \\
\hline \multicolumn{5}{|c|}{ Knowledge about PPIUCD } \\
\hline Not knowledgeable & 28 & 127 & 1.00 & 1.00 \\
\hline Knowledgeable & 112 & 153 & $3.3(2.1-5.35)^{*}$ & $1.64(0.8-3.3)$ \\
\hline \multicolumn{5}{|c|}{ Attitude towards PPIUCD } \\
\hline Negative attitude & 96 & 155 & 1.00 & 1.00 \\
\hline Positive attitude & 44 & 125 & $0.6(0.4-0.87)^{*}$ & $1.2(0.6-2.2)$ \\
\hline \multicolumn{5}{|c|}{ Counseled by a health-care provider } \\
\hline No & 14 & 159 & 1 & 1.00 \\
\hline Yes & 126 & 121 & $11.8(6.5-21.6)^{*}$ & $6.2(2.9-12.8)^{* *}$ \\
\hline
\end{tabular}

about this method as compared to other contraceptive methods.

Finally, the study also identified that women who had got counseling from health-care providers about postpartum intrauterine contraceptive devices significantly contribute to the uptake of the postpartum intrauterine contraceptive device. This finding is supported by the study done at four countries [16], Bhaktapur, Nepal [17], and in line with the 
study done at tertiary hospital Odisha, India [12], and the public health facility of Bale zone Ethiopia [6] and health center at Bahirdar, Ethiopia [5]. The possible justification could be that counseling by health-care providers may allow women to get accurate information about PPIUCD that can change their attitudes and behaviors by avoiding rumors and misconceptions, which may hinder the acceptance of postpartum intrauterine contraceptive devices to use. Therefore, avoiding this behavior through good and free counseling may motivate women to use the intrauterine contraceptive device during their postpartum period immediately after delivery.

\section{Limitation of Study}

This research was conducted only in public hospitals, the finding could not be used to generalize women who gave birth at home, health centers, and private health institutions, and there is no information regarding qualitative data. Another limitation of the study was that women might be discharged from the hospital before being interviewed so it was needed to actively follow and collect data from them before discharge.

\section{Conclusion}

The present study identified that completing secondary education, having a number of 3-4 and greater or equal to five children, attending three ANC visits during the last pregnancy, having ever heard about the postpartum intrauterine contraceptive device, and having counseling from health-care providers about postpartum IUCD as part of the contraceptive method were significantly associated with uptake of a postpartum intrauterine contraceptive device. The study recommends emphasizing the dissemination of information about the postpartum intrauterine contraceptive devices to women, encouraging women to attend at least secondary education, counseling women on postpartum IUCD during any contact, and motivating women to attend their ANC follow-ups.

\section{Data Availability}

The data sets generated during this study are available from the corresponding author upon reasonable request.

\section{Conflicts of Interest}

The authors who participated in this study declare that there are no conflicts of interest regarding the publication of this paper.

\section{Acknowledgments}

The authors would like to express their deepest gratitude to the University of Gondar, College of Medicine and Health Science, and School of Midwifery. This study was funded by University of Gondar.

\section{References}

[1] M. Jeffrey and B. smith, "Global postpartum reference manual Jhpiego corporation November 2010," 2010.

[2] M. Gaffield, S. Egan, and M. Temmerman, "It's about time: WHO and partners release programming strategies for postpartum family planning," Global Health: Science and Practice, vol. 2, no. 1, pp. 4-9, 2014.

[3] MR. Laskar Banerjee, "A study on IUCD insertion during the postpartum period (PPIUCD)," Age, vol. 20, no. 20, p. 15, 2016.

[4] MS. Harrison and RL. Goldenberg, "Immediate postpartum use of long-acting reversible contraceptives in low-and middle-income countries," Maternal Health, Neonatology, and Perinatology, vol. 3, no. 1, p. 24, 2017.

[5] S. Animen, S. Lake, and E. Mekuriaw, "Utilization of intrauterine contraceptive device and associated factors among the reproductive age group of family planning users in Han Health Center, Bahir Dar, North West Amhara, Ethiopia, 2018," BMC Research Notes, vol. 11, no. 1, p. 922, 2018.

[6] A. Gone, C. Worku, T. Assefa et al., "Acceptability and factors associated with post-partum IUCD use among women who gave birth at bale zone health facilities, Southeast-Ethiopia," Contraception and Reproductive Medicine, vol. 3, no. 1, p. 16, 2018.

[7] L. Tefera, M. Abera, C. Fikru, and D. Tesfaye, "Utilization of immediate post-partum intrauterine contraceptive device and associated factors: a facility-based cross-sectional study among mothers delivered at public health facilities of Sidama zone, south Ethiopia," Journal of Pregnancy and Child Health, vol. 4, no. 3, p. 326, Article ID 1000326, 2017.

[8] S. Pradhan, K. Jaya Singh, R. Sen, A. Aparajita Behera, and R. Madhab Tripathy, "Determinants for the uptake of the postpartum intrauterine contraceptive device among women delivering in tertiary hospitals, Odisha, India," International Journal of Reproduction, Contraception, Obstetrics, and Gynecology, vol. 6, no. 5, 2017.

[9] Organization WHO, WHO Medical Eligibility Criteria Wheel for Contraceptive Use, WHO, Geneva, Switzerland, 2015.

[10] Central Statistical Agency, Ethiopia Demographic and Health Survey 2016: Key Indicators Report, Central Statistical Agency, Addis Ababa, Ethiopia, 2016.

[11] AV. Kanhere, P. Pateriya, and M. Jain, "Acceptability and feasibility of immediate postpartum IUCD insertion in a tertiary care center in Central India," International Journal of Reproduction, Contraception, Obstetrics and Gynecology (IJRCOG), vol. 4, no. 1, pp. 179-184, 2015.

[12] S. Pradhan, S. Kshatri, A. Behera, and M. Tripathy, "Determinants of uptake of the post-partum intra-uterine contraceptive device among women delivering in a tertiary hospital, Odisha, India," International Journal of Reproduction, Contraception, Obstetrics, and Gynecology, vol. 6, no. 20, pp. 2320-1770, 2017.

[13] G. I. Eluwa, R. Atamewalen, K. Odogwu et al., "Success providing postpartum intrauterine devices in private-sector health care facilities in Nigeria: factors associated with uptake," Global Health: Science and Practice, vol. 4, no. 2, pp. 276-283, 2016.

[14] P. A. R. DarmayantiDN. Wirawan Sari et al., "Differences in post-placental intrauterine device acceptance with and without couples counseling in private practice midwifery clinics, West Denpasar," Public Health and Preventive Medicine Archive, vol. 6, no. 1, 1 page, 2018. 
[15] FMOH, Management Protocols on Selected Obstetric Topics, FMOH, Addis Ababa, Ethiopia, 2010.

[16] A. Makins, N. Taghinejadi, M. Sethi, K. Machiyama et al., "Factors influencing the likelihood of acceptance of postpartum intrauterine devices across four countries: India, Nepal, Sri Lanka, and Tanzania," International Journal of Gynecology \& Obstetrics, vol. 143, pp. 13-19, 2018.

[17] B. Khatri, A. Khadka, A. A.. S. M. Shrestha, and R. Paudel, "Perception and use of intrauterine contraceptive devices (IUCD) among married women of reproductive age in Bhaktapur, Nepal," Open Access Journal of Contraception, vol. 10, p. 69, 2019. 